\title{
A FRAGMENTAÇÃO DA DOCUMENTAÇÃO FERROVIÁRIA: UMA PERSPECTIVA LEGAL
}

THE FRAGMENTATION OF RAILWAY DOCUMENTATION: A LEGAL PERSPECTIVE

Enviado em 14 de outubro de 2014 Aceito em 7 de junho de 2015

Lucina Matos ${ }^{1}$

Resumo: Este trabalho debate a preservação do patrimônio documental da malha ferroviária brasileira tendo como recorte o processo de extinção da Rede Ferroviária Federal S.A (RFFSA). Essa empresa vem sendo privatizada desde 1992 e seu patrimônio arquivístico sofreu orientações diversas no que se refere a sua destinação e uso. Múltiplos agentes públicos foram envolvidos e, em 2007, a Lei $n^{\circ} 11.483$ decretou ao Instituto do Patrimônio Histórico e Artistíco Nacional (Iphan) a responsabilidade sobre a memória ferroviária, incluindo nesse grupo o passivo documental da Rede. Esta pesquisa tem buscado compreender o cenário estabelecido a partir dessas mudanças e os diversos atores envolvidos, inclusive organizações sociais como os movimentos de preservação ferroviária, e como os mesmos têm lidado com a questão. Assim, este texto fundamenta-se em dois pilares: apresentar um resumo dos regulamentos jurídicos e dos diversos "tutores" do patrimônio arquivístico e questionar a participação dos organismos arquivísticos nacionais na problemática da "fragmentação documental".

Palavra-chave: Patrimônio documental. Rede Ferroviária Federal S.A.. Preservação.

Abstract: The subject of this paper is the preservation of the documentary heritage of the Brazilian rail road system. The paper focuses on the dismantling of the Federal Railway Network (Rede Ferroviária Federal S.A. (RFFSA)) which was privatized in 1992. The company's archival heritage suffered changes regarding the destination and usage of its documents. Multiple government departments were involved, and in 2007 Law No. 11.483 officially entrusted responsibility for the safekeeping and administration of the rail system's archival memory to the National Historic and Artistic Heritage Institute (Instituto do Patrimônio Histórico e Artístico Nacional (IPHAN)). This body of

1 Doutoranda em História, Política e Bens Culturais pelo Centro de Pesquisa e Documentação de História Contemporânea do Brasil - CPDOC/FGV. Rio de Janeiro. E-mail: lucmatos2003@yahoo.com.br 
materials included the documentary archive of RFFSA. This research project seeks to understand the new scenario brought about by these changes, as well as understand the several protagonists such as social organizations, and railway preservation groups, and their actions. This text is divided among two pillars: presentation of a summary of the legal regulations and the actors responsible for archival heritage, as well as verification of the participation of national archival agencies in tackling the problem of "documentary fragmentation".

Keywords: Documentary heritage. Rede Ferroviária Federal S.A.. Preservation.

\section{APRESENTAÇÃO}

Este artigo tem como objetivo iniciar um diálogo sobre as condições de preservação dos documentos que registram uma parcela significativa da história das ferrovias brasileiras. A Rede Ferroviária Federal S.A. (RFFSA) foi criada em 1957 com o propósito de viabilizar melhores condições para a operação do transporte sobre trilho no país. Ela resultou da unificação de 22 empresas que operavam as estradas de ferro existentes à época. A Rede foi inserida no Programa Nacional de Desestatização (PND) no ano de 1992 e em 2007 foi decretado a sua extinção após uma sequência de etapas com vistas à dissolução, liquidação e extinção do objeto social da empresa exigidos pelo Programa. Uma das determinações desse processo foi a concessão das linhas operadas pela Rede para a iniciativa privada e a distribuição de um conjunto de tarefas obrigatórias para a desestatização da Rede a diversos órgãos públicos.

Por um período de 35 anos a Rede representou a maior referência da operação ferroviária no país e o processo da sua extinção suscita dúvidas sobre os prejuízos que essa opção causou e ainda causará na questão da preservação da sua memória. Descrevo alguns exemplos que demonstram os danos na salvaguarda do patrimônio documental decorrentes dessa nova reformulação na gestão da malha ferroviária brasileira. Essas observações nasceram respaldadas nas denúncias realizadas pelo Movimento de Preservação Ferroviária (MPF)², entidade existente na cidade do Rio de Janeiro com objetivo de promover debates sobre a preservação ferroviária, e, no estudo que realizo para o doutorado no âmbito do Programa de Pós-Graduação em História, Política e bens Culturais.

Com base na leitura de autores como José Maria Jardim (1995; 1996) e Lucina Matos (2010), aponto o início daquilo que chamo de problemática da fragmentação, narrando o processo de desestatização com base nas legislações referentes e em

\footnotetext{
${ }^{2}$ Conforme registrado no Informativo AFPF de julho de 2004.
} 
estudo sobre a história das ferrovias, para depois descrever as normas que orientaram a extinção propriamente dita. Por fim, descrevo a localização dos arquivos da Rede e seus novos responsáveis buscando reforçar a ideia de uma fragmentação irrecuperável. Essa reflexão está embasada nas disposições disciplinares emanadas da Arquivologia e nas orientações e normativas fornecidas pelo Arquivo Nacional e pelo Conselho Nacional de Arquivos (Conarq). A escrita do artigo contou com os estudos da história ferroviária tomando como referências Renê Fernandes Schoppa (2008), José Geraldo Esquerdo Furtado (2009), Andréa Casa Nova Maia (2010). No que tange ao conhecimento sobre patrimônio e memória, que subsidiam a escrito do texto, recorri as obras de Michael Pollak (1992; 2008), Ângela de Castro Gomes (1996), Jô Gondar (2005), Maria Cecília Londres Fonseca (2003), Luciana Quillet Heymann (2007) e Mário Chagas (2005).

\section{OS INDÍCIOS DA FRAGMENTAÇÃO}

Há aproximadamente quinze anos a Rede Ferroviária entrou em processo de extinção e, para cumprir os trâmites obrigatórios à dissolução/liquidação/extinção, deveria seguir uma sequência de orientações administrativas/legais relativas ao seu patrimônio. Nesse conjunto foi inserido o seu acervo arquivístico, tanto o conjunto de documentos caracterizados como correntes quanto os de valor histórico. Muitos são os relatos e as demonstrações do descaso que permitiram a perda alarmante de documentos da história ferroviária reforçado por essa decisão governamental. Como exemplo, em seminários realizados pelo Movimento de Preservação Ferroviária (MPF), são divulgados casos de extravio, perdas e danos ocorridos em alguns estados do Brasil, que possuíram conexão com os trilhos. Na cidade de Campos dos Goytacazes/RJ há registros em fotografias de dois antigos vagões contendo papeis deteriorados. Os documentos estavam espalhados por todo o vagão e no seu entorno, molhados e com aparência de queimados. Já na oficina ferroviária de Porto Novo, em Além Paraíba/MG é apontado o caso de roubos de documentos.

Outro caso relatado constantemente refere-se ao acervo técnico da empresa, que segundo os integrantes do MPF encontram-se encaixotados no prédio do escritório central da extinta Rede Ferroviária, na Central do Brasil/RJ. Isso impossibilita o acesso, que, segundo os mesmos, poderia subsidiar projetos recentes como as obras do "Porto Maravilha", relativas à implantação dos bondes que percorrerão o centro da cidade.

Tantos casos ouvidos desperta a atenção às diretrizes para a extinção da empresa que promove, pela morosidade e falta de articulação entre os atores envolvidos, o risco iminente aos bens históricos. Porém, em contraponto, os autores 
Raimunda Sousa e Haroldo Prates ( $\mathrm{s} / \mathrm{d}$ ) consideram que o processo de desestatização da Rede foi positivo, além de exemplificar uma metodologia inovadora no tratamento de empresas que passam por processos análogos de desestatizações ou privatizações. Para eles, o principal ganho no caso da Rede foi o fato dessa medida contribuir para "superar um importante gargalo para o crescimento econômico do país". Qualificam as medidas empregadas ao caso da Rede como um marco regulatório histórico nas questões de concessão de serviços públicos para a esfera privada. Portanto, para os autores, esse processo foi particularmente bem desenvolvido, em nada se comparando aos outros casos ocorridos no país.

Independentemente de resultados positivos - no que se refere ao processo propriamente dito -, que pode ter garantido benefícios tanto ao Estado quanto aos novos operadores da malha ferroviária brasileira, quero tratar aqui das orientações relativas ao acervo documental da Rede, as quais considero como promotoras de uma fragmentação irrecuperável. De tal modo, descreverei abaixo as primeiras medidas legislativas que abordaram tal questão, com objetivo de respaldar os meus argumentos e reconstruir, por meio dessa trajetória, a linha que sustenta os danos que identifico como prejudiciais à memória ferroviária e, sirva de subsídio para repensarmos o modo como o estado brasileiro opera com empresas em processos de desestatizações/privatizações no País.

\section{AS REGULAMENTAÇÕES PARA EXTINÇÃO DA REDE FERROVIÁRIA}

Em 1981 o governo brasileiro criou o Programa Nacional de Desestatizações por meio da Lei n 8.031, revogada em 1997 pela Lei n 9.491. O Programa tinha como objetivos:

I- Reordenar a posição estratégica do Estado na economia, transferindo à iniciativa privada atividades indevidamente exploradas pelo setor público;

II- Contribuir para a reestruturação econômica do setor público, especialmente através da melhoria do perfil e da redução da divida pública líquida;

III- Permitir a retomada de investimentos nas empresas e atividades que vierem a ser transferidas à iniciativa privada;

IV- Contribuir para a reestruturação econômica do setor privado, especialmente para a modernização da infra-estrutura e do parque industrial do País, ampliando sua competitividade e reforçando a capacidade empresarial nos diversos setores da economia, inclusive através da concessão de crédito; 
V- Permitir que a Administração Pública concentre seus esforços nas atividades em que a presença do Estado seja fundamental para a consecução das prioridades nacionais;

VI- Contribuir para o fortalecimento do mercado de capitais, através do acréscimo da oferta de valores mobiliários e da democratização da propriedade do capital das empresas que integrarem o Programa.

Com base nesses argumentos, o governo incluiu um conjunto de empresas controladas, direta ou indiretamente, pela União nesse programa. Dentre elas, a Rede Ferroviária Federal que foi inserida em 1992, por meio do Decreto n 473, que ainda incluiu a Agef Rede Federal de Armazéns Gerais Ferroviários S.A. e a Valec Engenharia, Construções e Ferrovias S.A.. Para cumprir as exigências da desestatização, a Rede Ferroviária foi dissolvida em 1999, por meio do Decreto n 3.277. Essa mesma medida legislativa determinou os procedimentos para a sua liquidação, estabelecendo os procedimentos para a indicação do liquidante da empresa e suas atribuições administrativas, definindo a comissão de liquidação, o corpo funcional que operaria junto a esta etapa, bem como os prazos que deveriam ser cumpridos.

A fase de liquidação foi seguida de várias alterações de prazos para a sua finalização, sobretudo pela não constituição da comissão de liquidação, estabelecida em 2005 pelo Decreto n 5.476, após inúmeras tentativas.

Em 2007, após esse longo trajeto, é decretado o fim da liquidação e a extinção da Rede Ferroviária que, com essa medida, entra em processo de inventariança. No emaranhado de funções, atividades e atribuições oriundas das determinações legais instituídas pela Medida Provisória n 353/07, que dispõe sobre término do processo de liquidação, pelo Decreto n 6.018/07 que regulamenta essa MP e pela Lei n 11.483, que trata da revitalização do setor ferroviário, identifiquei as definições que impactaram o acervo documental da empresa.

\section{A REGULAMENTAÇÃO LEGISLATIVA E AS DISTRIBUIÇÕES DOCUMENTAIS}

Inicio pela MP 353/07, que dispõe sobre os direitos, obrigações e bens patrimoniais da empresa que passam para a gestão da União, garantido os direitos dos acionistas minoritários. O Ministério dos Transportes ficou responsável pela coordenação e supervisão do inventário do objeto social que deveria ser esvaziado para sua extinção completa. O liquidante foi substituído pelo inventariante. Para que essa etapa fosse executada, foi instituído no Ministério da Fazenda o Fundo Contigente 
( $R \$ 3$ 300.000.000,00), uma espécie de reserva financeira para prover pagamentos oriundos de despesas administrativas e judiciais. Também, determina que a empresa Valec, inserida no PND junto com a Rede, assuma a sucessão trabalhista daquela. Esse fundo poderia ser utilizado como subsídio para a organização das etapas de organização documental, também. Estas não foram cumpridas até os dias atuais. A mudança constante do liquidante/inventariante da empresa promove uma dificuldade na finalização do processo e nas decisões que devem ser seguidas em relação ao patrimônio histórico.

O instrumento que regulamenta a MP 353 - o Decreto 6.108/07 -, no seu Art. 3o descreve as atribuições do inventariante de forma a cumprir as determinações dessa norma. Há um grande número de fazeres, regulados pelo Arquivo Nacional, que deveriam ser cumpridos para a transferência de documentos da extinta Rede para órgãos sucessores. Dentre as competências do inventariante há dois itens que resumem as suas atribuições funcionais especificamente naquilo que tange ao acervo: "apurar os direitos e obrigações, assim como relacionar documentos, livros contábeis, contratos e convênios da extinta RFFSA, dando-lhes as destinações previstas neste Decreto" (Art. 3ㅇ, IV). E, o de "providenciar o tratamento dos acervos técnicos, bibliográficos, documentais e de pessoal, observadas as normas específicas, transferindo-os, mediante termo próprio, ao Arquivo Nacional ou aos órgãos e entidades que tiverem absorvido as correspondentes atribuições da extinta RFFSA" (Art. 3ํ, VII). Até aonde busquei informações junto a ambas as entidades (RFFSA e Arquivo Nacional) esta atribuição ainda não foi cumprida. Mas, é interessante observar que a regulamentação legal reconhece as competências e critérios técnicos do Arquivo Nacional.

Vale sublinhar que em todas as determinações de sucessão das tarefas antes realizadas pela Rede estão embutidas questões relacionadas à transferência de responsabilidade sobre os documentos, seja em caráter provisório ou definitivo. Importa aqui destacar aqueles que causaram maior impacto naquilo que chamo de fragmentação documental e que se encontram de forma explícita na Legislação.

Ao Departamento Nacional de Infraestrutura de Transportes (DNIT) deveria ser transferido o acervo documental relativo aos bens móveis e imóveis operacionais, os bens móveis não-operacionais existentes na Administração Geral da Rede (Central do Brasil/RJ) e nos escritórios regionais, além de todos os bens móveis não-operacionais, sem destino definido na MP 353/07 e nos Termos de Ajustes de Condutas (TAC) celebrados entre a Rede e o Ministério Público. O Ministério do Planejamento, Orçamento e Gestão receberia o conjunto documental relativo aos dossiês funcionais 
de empregados aposentados e pensionistas, bem como a documentação dos imóveis não-operacionais.

À Valec deveriam ser transferidos os documentos dos empregados ativos e aqueles necessários à operação da folha de pagamento de pessoal, além dos referentes a ações judiciais relacionadas a processos de pessoal caracterizados como ativos. Esse órgão, também ficou responsável pelos documentos que representavam relações de patrocínio para a REFER. A Advocacia-Geral da União absolveu os acervos relativos às ações judiciais em trâmite, com exceção dos direcionadas à Valec. Ao Instituto do Patrimônio Histórico e Artístico Nacional (Iphan) seriam transferidos os convênios "firmados com entidades de direito público ou privado que tenham por objeto a exploração e administração de museus ferroviários e de outros bens de interesse artístico, histórico e cultural" (Decreto 6.018, Art. 5ㅇ, IV-b). À Agência Nacional de Transportes Terrestres (ANTT) deveriam ser encaminhados os contratos de arrendamento.

Como se pode observar por essa breve descrição, a questão documental permeia todas as atividades que devem ser executadas pelo inventariante da Rede Ferroviária. Interessa-me destacar, sobretudo, a pulverização do acervo documental promovida pelo processo de desestatização da Rede Ferroviária. Este mesmo processo pode ter ocorrido com outras empresas desestatizadas no país, o que apenas ratifica a importância do debate acerca do acervo da Rede.

Além de todos os problemas que tal fragmentação acarreta para o cumprimento dos procedimentos da gestão documental e para o respeito a alguns princípios da Arquivologia, esse panorama pode indicar um problema futuro no que se refere à pesquisa histórica. Ou seja, daqui a alguns anos um pesquisador interessando na história da ferrovia pode se deparar com um problema de mapeamento das fontes para sua pesquisa, além de correr o sério risco de, simplesmente, não conseguir localizar os documentos.

A Arquivologia possui um conjunto de teorias e princípios que fundamentam e orientam as atividades do campo. O "princípio do respeito aos fundos" ou "princípio da proveniência" é um de seus critérios balizadores. Segundo ele, conjuntos documentais acumulados no cumprimento das atividades de uma empresa/instituição pública ou privada, ou mesmo por uma pessoa, devem ter respeitados os seus limites, não devendo ser agrupados a fundos produzidos por outras entidades. É necessário preservar a origem documental sob o risco de perder a identidade dos fundos e dificultar o acesso e a pesquisa nos arquivos.

Cada empreendimento humano, seja ele comercial ou social, produz ao longo de sua existência conjuntos de eventos registrados em variados tipos de suportes que 
formam, no seu todo, o seu acervo documental, comumente chamado de fundo. De ordem corrente, intermediária ou permanente, servindo à administração ou à pesquisa histórica, social ou cultural há de ser observado e respeitado no tratamento documental o sujeito produtor. Isso significa dizer que o fundo documental é indivisível; não pode ser disperso, pois os documentos guardam relações entre si e só no seu agrupamento total representam a história do organismo produtor. É necessário preservar a origem documental sob o risco de perder a identidade dos fundos e dificultar o acesso e a pesquisa nos arquivos.

Pela análise do caso da Rede Ferroviária, entendo que qualquer empresa ou serviço gerido pelo Estado que passe para a gestão privada ou que entre em processo de extinção - sendo a atividade desempenhada, obrigatoriamente, transferida para outro órgão público - implica em fragmentação documental ferindo, principalmente, o respeito ao fundo arquivístico. Nesse sentido, acredito que as regulamentações oriundas desses processos administrativos devem considerar a preservação desses registros, evitando que sejam dispersos. Assim, entendo que uma solução admissível seria a determinação legal que obrigue o tratamento desse conjunto documental destinando o recolhimento futuro às instituições de guarda o que permitiria o seu reagrupamento.

\section{A ATUAÇÃO DOS ÓRGÃOS ARQUIVÍSTICOS}

Nesse sentido, gostaria de abordar um projeto, ainda incipiente, iniciado pelo agente público que tem autoridade para legislar sobre esse assunto - O Conselho Nacional de Arquivos (Conarq). Esse órgão está vinculado ao Arquivo Nacional e tem como função "definir a política nacional de arquivos públicos e privados, bem como exercer orientação normativa visando à gestão documental e à proteção especial aos documentos de arquivo" (Decreto 4.073). Segundo o seu regulamento legal o Conarq pode constituir câmaras técnicas e comissões especiais que teriam como objetivo

[...] elaboar estudos, normas e outros instrumentos necessários à implementação da política nacional de arquivos públicos e privados e ao funcionamento do SINAR, bem como câmaras setoriais, visando a identificar, discutir e propor soluções para questões temáticas que repercutirem na estrutura e organização de segmentos específicos de arquivos, interagindo com as câmaras técnicas (DECRETO 4.073/02, Art. 7)

O Decreto 2.942/99 que regulamentou o art. 7, 11 e 16 da Lei 8.159/91 descreve no seu Art. 40 que "Os documentos públicos de valor permanente, que integram o acervo arquivístico das empresas em processo de desestatização, parcial ou total, serão 
recolhidos a instituições arquivísticas públicas, na sua esfera de competência, por serem inalienáveis e imprescindíveis". Para isto, o recolhimento deve constituir edital específico na desestatização, exigência cumprida no caso da Rede Ferroviária. Além disso, as empresas incluídas nesses processos devem providenciar "em conformidade com as normas arquivísticas emanadas do Conselho Nacional de Arquivos - CONARQ, a identificação, classificação e avaliação do acervo arquivístico" (Dec. 2.942, Art. 4ㅇ, §2), obrigação ainda não cumprida pela Rede, segundo o Arquivo Nacional.

O Conarq criou em 2002, por meio da Portaria 67, uma câmara setorial para tratar dos arquivos de empresas privatizadas ou em processo de privatização. Segundo a Portaria, essa comissão deveria "propor instrumentos legais, normas e procedimentos técnicos, visando à gestão, fiscalização, preservação e acesso aos acervos públicos de valor permanente sob a guarda de pessoas jurídicas de direito privado, sucessoras de empresas públicas, e daquelas em processo de desestatização parcial ou total, bem como promover a disseminação das informações neles contidos". Essa câmara deveria se reunir a cada quatro meses e registrar suas decisões em ata. Infelizmente, pouco tem sido realizado por esse grupo, caracterizando-se como uma das câmaras com menor contribuição para os debates dentro do Conselho. Considero que este seria o espaço primordial para os debates sobre o tratamento dos processos de privatizações/desestatizações, como a própria proposta de sua criação indica. Porém, sem atuação torna-se apenas mais uma proposta infrutífera, permitindo sucessivas críticas à eficiência das políticas públicas no campo arquivístico.

\section{CONSIDERAÇÕES FINAIS}

No Brasil vigora desde 1991 a Lei 8.159, conhecida como a Lei de Arquivo, cujo objetivo é divulgar, promover e, principalmente, estabelecer políticas públicas concernentes à gestão dos arquivos públicos e privados no país. Cumprindo premissas apontadas pela Constituição Federal de 1988 no que se refere à acessibilidade, essa norma legal foi considerada um avanço significativo para o país. Ela trata de assuntos como a definição do que são arquivos públicos e privados, bem como, orienta sobre as competências administrativas dos órgãos na esfera pública.

As breves notas reunidas nesse artigo têm como objetivo principal chamar atenção para dimensões nas quais ainda precisamos avançar. $O$ caso do acervo documental da Rede Ferroviária aponta limites importantes na ação dos órgãos competentes no que diz respeito à preservação e gestão dos documentos de natureza pública. Ao mesmo tempo, indica que não é suficiente legislar e criar instâncias normativas. Ainda que necessárias, tais medidas apenas se tornarão efetivas se vierem 
acompanhadas de um investimento concreto por parte dos órgãos públicos, congregando a sociedade civil interessada e os profissionais da área.

\section{REFERÊNCIAS}

ASSOCIAÇÃO FLUMINENSE DE PRESERVAÇÃO FERROVIÁRIA. Informativo AFPF, no 61, jul./04.

BRASIL. Decreto № 2.942, de 18 de janeiro de 1999. Regulamenta os arts. 7으, 11 e 16 da Lei no 8.159, de 8 de janeiro de 1991, que dispõe sobre a política nacional de arquivos públicos e privados e dá outras providências. Diário Oficial da República Federativa do Brasil, Brasília, DF, 19 de janeiro de 1999. Disponível em:<http://www.planalto.gov.br/ccivil_03/decreto/D2942. $\mathrm{htm}>$. Acesso em 20 de set. 2013.

BRASIL. Decreto no 4.073, de 3 de janeiro de 2002. Regulamenta a Lei no 8.159, de 8 de janeiro de 1991, que dispõe sobre a política nacional de arquivos públicos e privados. Diário Oficial da República Federativa do Brasil, Brasília, DF, 4 de janeiro de 2002. Disponível em:<http://www. planalto.gov.br/ccivil_03/decreto/2002/d4073.htm>. Acesso em 20 de set. 2013.

. Lei no 3.115, de 16 de mar. 1957. Determina a transformação das empresas ferroviárias da União em sociedades por ações, autoriza a constituição da Rede Ferroviária S.A., e dá outras providências. Diário Oficial da República Federativa do Brasil, Brasília, DF, 16 de mar. 1957. Disponível em: <http://www.planalto.gov.br/CCIVIL/LEIS/L3115.htm>. Acesso em 20 de set. 2013.

. Lei. no 8.159, de 8 de janeiro de 1991. Dispõe sobre a política nacional de arquivos públicos e privados e dá outras providências. Diário Oficial da República Federativa do Brasil, Brasília, DF, 08 de jan. 1991. Disponível em: <http://www.planalto.gov.br/ccivil/Leis/L8159. htm>. Acesso em 20 de set. 2013.

. Decreto no 473, de 9 de março 1992. Dispõe sobre a inclusão, no Programa Nacional de Desestatização - PND, da Rede Ferroviária Federal S.A.-RFFSA, da AGEF - Rede Federal de Armazéns Ferroviários S.A. e da Valec-Engenharia, Construções e Ferrovias S.A. Diário Oficial da República Federativa do Brasil, Brasília, DF, 10 de mar. 1992. Disponível em: <http://www. planalto.gov.br/CCIVIL_03/decreto/1990-1994/D0473.htm>. Acesso em 20 de set. 2013 .

. Lei $n^{\circ} 9.491$, de 09 de setembro de 1997. Altera procedimentos relativos ao Programa Nacional de Desestatização. Diário Oficial da República Federativa do Brasil, Brasília, DF, 10 dez. 1997. Disponível em: <http://www.planalto.gov.br/CCIVIL/IEIS/L9491.htm>. Acesso em 20 de set. 2013. 
. Decreto no 3.277, de 07 de dezembro 1999. Dispões sobre a dissolução, liquidação e extinção da Rede Ferroviária Federal S.A. - RFFSA. Diário Oficial da República Federativa do Brasil, Brasília, DF, 07 de dez. 1999. Disponível em: <http://www.planalto.gov.br/ccivil_ 03/decreto/D3277.htm>. Acesso em 20 de set. 2013.

. Decreto no 5.476, de 23 de junho de 2005. Altera e acresce dispositivos ao Decreto no 3.277, de 7 de dezembro de 1999, que dispõe sobre a dissolução, liquidação e extinção da Rede Ferroviária Federal S.A - RFFSA. Diário Oficial da República Federativa do Brasil, Brasília, DF, 23 de junho de 2005. Disponível em:<http://www.planalto.gov.br/ccivil_03/_ato2004-2006/2005 /Decreto/D5476.htm>. Acesso em 20 de set. 2013.

Medida Provisória no 353, de 22 de janeiro de 2007. Dispõe sobre o término do processo de liquidação e a extinção da Rede Ferroviária Federal S.A. - RFFSA, altera dispositivo da Lei. no 10.233, de 5 de julho de 2001, e dá outras providências. Diário Oficial da República Federativa do Brasil, Brasília, DF, 22 de janeiro de 2007. Disponível em:<http://www.planalto. gov.br/ccivil_03/_ato2007-2010/2007/Mpv/353.htm>. Acesso em 20 de set. 2013.

. Decreto no 6.018, de 22 de Janeiro de 2007. Regulamenta a Medida Provisória no 353, de 22 de janeiro de 2007, que dispõe sobre o término do processo de liquidação e a extinção da Rede Ferroviária Federal S.A. - RFFSA, altera dispositivos da Lei no 10.233, de 5 de junho de 2001, e dá outras providências. Diário Oficial da República Federativa do Brasil, Brasília, DF, 22 de jan. 2007. Disponível em: <http://www.planalto.gov.br/ccIVIL_03/_Ato2007-2010/2007/ Decreto/D6018.htm>. Acesso em 20 de set. 2013.

. Lei no 11.483, de 31 de maio 2007. Dispõe sobre a revitalização do setor ferroviário, altera dispositivos da Lei no 10.233, de 5 de junho de 2001, e dá outras providências. Diário Oficial da República Federativa do Brasil, Brasília, DF, 31 de maio 2007. Disponível em: <http://www.planalto.gov.br/CCIVIL/_Ato2007-2010/2007/Lei/L11483.htm>. Acesso em 20 de set. 2013.

. Decreto no 6.769, de 10 de fevereiro 2009. Dá nova redação aos arts, 5ㅇ, 6으 e 7으 do Decreto no 6.018, de 22 de janeiro de 2007, que regulamenta a Medida Provisória no 353, de 22 de janeiro de 2007, convertida na Lei no 11.483, de 31 de maio de 2007, que dispõe sobre a revitalização do setor ferroviário e dá outras providências. Diário Oficial da República Federativa do brasil, Brasília, DF, 11 de fevereiro 2009. Disponível em :<http://www.planalto. gov.br/ccivil_03/_Ato2007-2010/2009/Decreto/D6769.htm>. Acesso em 20 de set. 2013.

CHAGAS, Mário. Cultura, Patrimônio e Memória. Revista Museu. 2005. Disponível em: <http://www.revistamuseu.com.br/18demaio/artigos.asp?id=5986>. Acesso em: 15 de jun. 2013. 
FONSECA, Maria Cecília Londres. Para além de pedra e cal: por uma concepção ampla de patrimônio cultural. In: ABREU, Regina; CHAGAS, Mario (org.). Memória e patrimônio. Rio de Janeiro: DP\&A, 2003. p.56-76.

FURTADO, José Geraldo Esquerdo. Oficina de memória: a construção do espaço de trabalho nas narrativas dos ferroviários de Porto Novo. Dissertação de Mestrado em Memória Social. Universidade Federal do Estado do Rio de Janeiro - UNIRIO, 2009.

GOMES. Ângela de Castro. A Guardiã da Memória. Disponível em: < http://cpdoc.fgv.br/ producao_intelectual/arq/538.pdf>. Acesso em: 20 de jun. 2013.

GONDAR, Jô. Quatro Proposições sobre Memória Social, In: GONDAR, Jô; DODEBEI, Vera. 0 que é memória social. Rio de Janeiro: Unirio, 2005, p. 11-26.

HEYMANN, Luciana Quillet. O devoir de mémoire na França contemporânea: entre memória, história, legislação e direitos. In: GOMES, Angela de Castro (Coord.). Direitos e cidadania: memória, política e cultura. Rio de Janeiro: Editora FGV, 2007.

JARDIM, José Maria. Sistemas e Políticas Públicas de Arquivo no Brasil. Niterói: EDUFF, 1995. . A Invenção da Memória nos Arquivos Públicos. Revista Ciência da Informação. Rio de Janeiro, v 25, n 02, 1996.

LIMA, Pablo Luiz de Oliveira. Ferrovia, sociedade e cultura. Belo Horizonte: Argumentum, 2009. MAIA, Andréa Casa Nova. Memória sobre trilhos: culturas e identidades ferroviárias no Brasil. Disponível em: <http://web.letras.up.pt/aphes29/data/8th/AndreaCasaNova_Texto2.pdf>. Acesso em 20 jun. 2013.

MATOS, L. F. Estação da Memória: um estudo das entidades de preservação ferroviária do Estado do Rio de Janeiro. Programa de Pós-graduação em História, Política e Bens Culturais. CPDOC/FGV.

POLLAK, Michael. Memória e identidade social. Estudos Históricos, Rio de Janeiro, vol. 5, № 10, 1992, p.200-212.

. Memória, esquecimento, silêncio. Estudos Históricos, Rio de Janeiro, 1989.

Disponível em: <http://www2.uel.br/cch/cdph/arqtxt/Memoria_esquecimento_silencio.pdf>. Acesso em: 20 de abr. 2013.

SCHOPPA, Renê Fernandes. 150 anos do trem no Brasil. Publicação independente, 2008. 
SOUSA, Raimunda Alves de; PRATES, Haroldo fialho. O processo de desestatização da RFFSA: principais aspectos e primeiros resultados. Disponível em:<http://www.bndes.gov.br/SiteBNDES /bndes/bndes_pt/Institucional/Publicacoes/Consulta_Expressa/Tipo/Revista_do_BNDES/19971 2_11.html>. Acesso em 10 de jul. de 2013 